\title{
Single-source-precursor synthesis of porous W-containing SiC-based nanocomposites as hydrogen evolution reaction electrocatalysts
}

\author{
Zhaoju YU ${ }^{a, *}$, Kangwei $\mathrm{MAO}^{a}$, Yao FENG ${ }^{b, c, *}$ \\ ${ }^{a}$ College of Materials, Key Laboratory of High Performance Ceramic Fibers (Xiamen University), \\ Ministry of Education, Xiamen 361005, China \\ ${ }^{b}$ Technische Universität Darmstadt, Institut für Materialwissenschaft, Otto-Berndt-Straße 3, \\ D-64287, Darmstadt, Germany \\ ${ }^{c}$ College of Materials Science and Engineering, Changsha University of Science \& Technology, \\ Changsha 410114, China
}

Received: February 17, 2021; Revised: June 8, 2021; Accepted: June 11, 2021

(c) The Author(s) 2021.

\begin{abstract}
In this paper, W-containing SiC-based ceramic nanocomposites were successfully prepared by a polymer-derived ceramic approach using allylhydridopolycarbosilane (AHPCS) as a SiC source, $\mathrm{WCl}_{6}$ as a tungsten source, polystyrene (PS) as a pore forming agent as well as divinyl benzene (DVB) as a carbon rich source. High-temperature phase behavior of the $\mathrm{W}$-containing SiC-based ceramics after heat treatment was studied, showing that excessive DVB content in the feed will inhibit the crystallinity of W-containing nanoparticles in the final ceramic nanocomposites. The high specific surface area (SSA) of $169.4-276.9 \mathrm{~m}^{2} / \mathrm{g}$ can be maintained even at high temperature in the range of $1400-1500{ }^{\circ} \mathrm{C}$, due to the carbothermal reaction which usually occurs between 1300 and $1400{ }^{\circ} \mathrm{C}$. All prepared $\mathrm{W}$-containing SiC-based nanocomposites reveal electrocatalytic activity for the hydrogen evolution reaction (HER). In detail, compared with reversible hydrogen electrode (RHE), the ceramic sample PWA-2-1300 after heat treatment at $1300{ }^{\circ} \mathrm{C}$ has the smallest overpotential of $286 \mathrm{mV}$ when the current density is $10 \mathrm{~mA} \cdot \mathrm{cm}^{-2}$ in acid medium, indicating the promising perspective in the water splitting field.
\end{abstract}

Keywords: single-source-precursor; W-containing phase; SiC-based nanocomposites; electrocatalyst; hydrogen evolution reaction

\section{Introduction}

Polymer-derived ceramic (PDC) approach started from the 1960s and is a versatile method used for the fabrication of mainly Si-based advanced ceramics [1,2]. During the past 60 years, due to their physical-

\footnotetext{
* Corresponding authors.

E-mail: Z.Yu, zhaojuyu@xmu.edu.cn;

Y. Feng, yao.feng@gast.tu-darmstadt.de
}

chemical [3,4] and thermomechanical properties [5] as well as their ability of being shaped using a wide variety of processing methods, PDCs have been explored widely for promising applications mainly including fibers [6,7], high-temperature-resistant materials [8-11], hard materials [12], chemical engineering (catalyst support, food- and biotechnology, etc.) [13,14], or functional materials in electrical engineering $[15,16]$ as well as in micro/nanoelectronics [17,18]. Particularly, PDC technology is convenient and efficient to produce 
micro/mesoporous ceramics as catalyst supports with high specific surface area (SSA) and outstanding corrosion stability [14,19-22].

Electrochemical water splitting as an efficient way of hydrogen manufacturing technologies can tackle the intense challenge of excessive depletion of fossil fuels due to its renewability and environmental friendliness $[23,24]$. Hydrogen evolution reaction (HER), as a crucial half-reaction of the electrochemical water splitting, requires an active electrocatalyst on cathodes to decrease the kinetic barrier and accelerate the reaction rate $[25,26]$. Despite platinum-group metal (such as $\mathrm{Pt}, \mathrm{Ru}, \mathrm{Rh}$, Ir, and $\mathrm{Pd}$ ) has been reported as outstanding and stable cathode catalysts for HER in both acidic and alkaline electrolytes, its practical applications for electrochemical water splitting are still very limited because of its high cost [26,27]. Thus, high-performance noble-metal-free catalysts, practically transition metal (group IV-VI) carbides [28,29], have attracted considerable attention recently, due to their Pt-like electronic and catalytic properties. Among them, tungsten carbides $\left(\mathrm{WC}, \mathrm{W}_{2} \mathrm{C}\right.$ ) and molybdenum carbides $\left(\mathrm{Mo}_{x} \mathrm{C}_{y}\right)$ are considered to be more active than other materials [30,31]. However, particularly for pure transition metal carbides, such as tungsten carbides, it is still difficult to synthesize a nanosized structure with high SSA, which not only decreases active sites but also hinders the diffusions of ions, electrolyte, and generated gas [32]. Thus, Fan et al. [33] reported that nanocrystalline WC on CNTs with high SSA exhibits better HER catalytic activity than that of pure WC.

Although great progress has been achieved for the research of transition metal carbide catalysts towards HER, there is little attention paid on HER electrocatalysts combining PDCs as supports with high SSA $[34,35]$. In our previous study [34], for the first time we reported on the in-situ formation of a nanosized $\mathrm{Mo}_{4.8} \mathrm{Si}_{3} \mathrm{C}_{0.6}$ embedded in a porous $\mathrm{SiC} / \mathrm{C}$-based matrix via a novel single-source precursor approach, which exhibited electrocatalytic activity and excellent durability in terms of the HER. Subsequently, in order to further improve the HER activity of the $\mathrm{Mo}_{4.8} \mathrm{Si}_{3} \mathrm{C}_{0.6} / \mathrm{C} / \mathrm{SiC}$ ceramic nanocomposites, DVB [35] was used as a rich carbon source to synthesize mesoporous $\mathrm{Mo}_{4.8} \mathrm{Si}_{3} \mathrm{C}_{0.6} /$ $\mathrm{C} / \mathrm{SiC}$ ceramic nanocomposites with higher carbon content, demonstrating superior HER performance. Herein, to further extend the application of PDCs in the field of water splitting, for the first time, we successfully synthesized W-containing SiC-based nanocomposites used as HER electrocatalysts by PDC approach using allylhydridopolycarbosilane (AHPCS) as a $\mathrm{SiC}$ source and tungsten hexachloride $\left(\mathrm{WCl}_{6}\right)$ as a tungsten source [36]. Besides, inspired by our previous study [34,35], polystyrene (PS) and divinylbenzene (DVB) were used as a pore former and a rich carbon source, respectively. What is more, the phase transformation of W-containing SiC-based nanocomposites annealed at $900-1500{ }^{\circ} \mathrm{C}$ were studied in detail.

\section{Experimental}

\section{1 Materials}

The AHPCS with a composition of $\left[\mathrm{SiH}_{1.26}\left(\mathrm{CH}_{3}\right)_{0.60}\left(\mathrm{CH}_{2} \mathrm{CH}=\mathrm{CH}_{2}\right)_{0.14} \mathrm{CH}_{2}\right]_{n}$ was synthesized according to our previous work [37]. Tungsten hexachloride $\left(\mathrm{WCl}_{6}\right)$, divinylbenzene (DVB), and polystyrene (PS, average $\left.M_{\mathrm{w}}=35,000\right)$ were purchased from Aldrich. The Ar atmosphere with a purity of 99.99\% was used as protective gas during pyrolysis and annealing process. Chloroform $\left(\mathrm{CHCl}_{3}\right.$, Xilong) was distilled before use. Other commercially available reagents were used as received.

\section{2 Synthesis of single-source-precursors}

One typical synthesis is described as follows. $1.00 \mathrm{~g}$ $\mathrm{WCl}_{6}, 4.00 \mathrm{~g}$ PS, and $2.00 \mathrm{~g}$ AHPCS were added into a Schlenk flask. Followed by five times of gas exchange, the flask was filled with Ar. Then, $3.00 \mathrm{~g} \mathrm{DVB}$ and $20 \mathrm{~mL} \mathrm{CHCl}{ }_{3}$ were injected into the flask, stirred at room temperature for $1 \mathrm{~h}$ to fully dissolve the reaction mixture. After stirring at room temperature for another $24 \mathrm{~h}$, the resultant solution was refluxed at $70{ }^{\circ} \mathrm{C}$ for $12 \mathrm{~h}$ to obtain black slurry sample. Finally, heating to $160{ }^{\circ} \mathrm{C}$ for $6 \mathrm{~h}$, the $\mathrm{W}$-containing precursor abbreviated as PWA-2 was obtained after the solvent was stripped off under vacuum. By adjusting the amount of DVB, a series of different samples were obtained. Sample notations and weight ratio of the reactants are listed in Table 1.

Table 1 Sample notations and weight ratio of the reactants for the synthesis of ceramic nanocomposites

\begin{tabular}{ccccc}
\hline Precursor & AHPCS $(\mathrm{g})$ & PS $(\mathrm{g})$ & $\mathrm{WCl}_{6}(\mathrm{~g})$ & $\mathrm{DVB}(\mathrm{g})$ \\
\hline PWA-1 & 2 & 4 & 1 & 2 \\
PWA-2 & 2 & 4 & 1 & 3 \\
PWA-3 & 2 & 4 & 1 & 4 \\
\hline
\end{tabular}




\section{3 Polymer-to-ceramic transformation}

The single-source-precursors were placed in a graphite boat and heated in the low-temperature furnace with quartz glass tube under an argon atmosphere, and the specific heating procedure is as follows: the precursors were heated from the room temperature with a rate of $2{ }^{\circ} \mathrm{C} / \mathrm{min}$ to $250{ }^{\circ} \mathrm{C}$, held for $2 \mathrm{~h}$ at $250{ }^{\circ} \mathrm{C}$, further heated to $500{ }^{\circ} \mathrm{C}$ with a rate of $2{ }^{\circ} \mathrm{C} / \mathrm{min}$, then heated to $900{ }^{\circ} \mathrm{C}$ with a rate of $5{ }^{\circ} \mathrm{C} / \mathrm{min}$, and held for $2 \mathrm{~h}$ at $900{ }^{\circ} \mathrm{C}$. Amorphous ceramic materials were obtained by natural cooling to the room temperature.

The amorphous ceramic materials were then put into a graphite boat and heated in a high-temperature furnace with an alumina tube under an argon atmosphere. The annealing process is carried out according to the following heating program: the materials were heated from room temperature to $900{ }^{\circ} \mathrm{C}$ with a rate of $5{ }^{\circ} \mathrm{C} / \mathrm{min}$, then heated to the target temperature (1300, 1400 , or $1500{ }^{\circ} \mathrm{C}$ ), and held for $2 \mathrm{~h}$, followed by cooling down to the room temperature. Crystalline ceramics at different temperatures could be obtained. The whole process from precursors to ceramic powders is shown in Fig. 1.

\section{4 Characterization}

The synthesis process of single-source-precursor was characterized by Fourier transform infrared spectra (FTIR, Nicolet, Madison, WI) with $\mathrm{KBr}$ tablet method in the range of $4000-500 \mathrm{~cm}^{-1}$. Elemental analysis of the ceramic powders was carried out by Horiba Carbon/Sulfur Analyzer EMIA-320 V (Horiba, Kyoto,

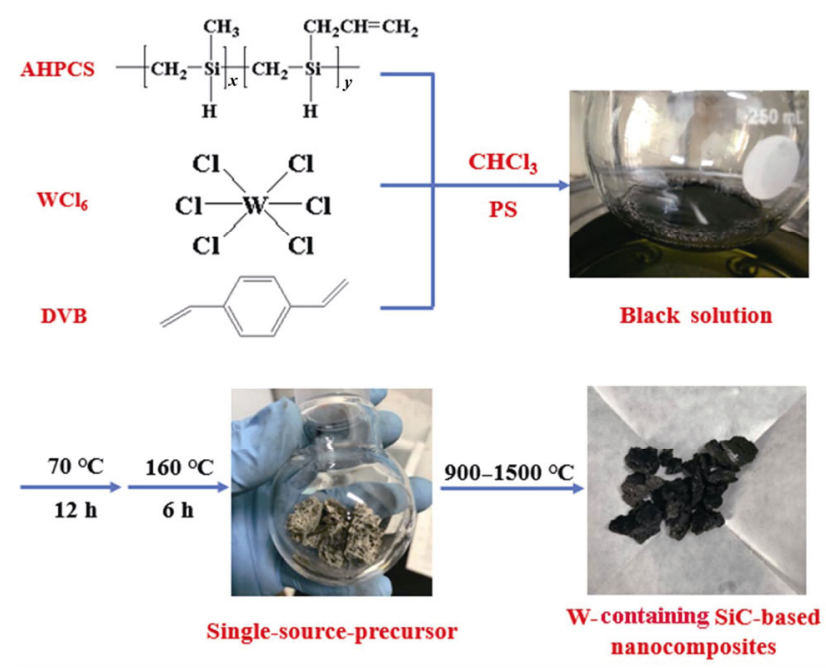

Fig. 1 Graphical synthesis of W-containing SiC-based nanocomposites.
Japan) for carbon element. Powder X-ray diffraction (XRD) experiments were recorded using a SmartLabSE powder diffractometer (Rigaku Corporation, Japan) with $\mathrm{Cu} \mathrm{K \alpha}$ radiation source. The specimens were continuously scanned from $10^{\circ}$ to $90^{\circ}(2 \theta)$ at a scanning speed of $10\left(^{\circ}\right) / \mathrm{min}$. The microstructure of the ceramics annealed at different temperatures was observed by transmission electron microscope (TEM, JEM-2100, JEOL, Tokyo, Japan) at an acceleration voltage of $200 \mathrm{kV}$. A micro-Raman spectrometer (XploRA, HORIBA Scientific) with a laser wavelength of $532 \mathrm{~nm}$ was used to record Raman spectra from 100 to $4000 \mathrm{~cm}^{-1}$. The nitrogen absorption and desorption curve and the BET specific surface area of the sample were obtained by the automatic specific surface and pore analysis tester (TriStar II3020, Micromeritics, USA). The nitrogen purity is $99.99 \%$ and the test temperature is $77 \mathrm{~K}$ (liquid nitrogen). Before the test, the sample was vacuum degassed at $120{ }^{\circ} \mathrm{C}$ for $12 \mathrm{~h}$ to remove the gas adsorbed on the sample surface. Electrochemical characterization was carried out in a three-electrode setup using an Interface 1000 potentiostat from Gamry Instruments. All the electrocatalysts were fixed on the top of the glassy carbon electrode with $5 \mathrm{wt} \%$ Nafion solution, with a weight density of $0.95-1.00 \mathrm{mg} / \mathrm{cm}^{2}$. Then, according to the specified test procedure, all catalysts were tested with $0.5 \mathrm{~mol} / \mathrm{L}$ $\mathrm{H}_{2} \mathrm{SO}_{4}$ (Carl Roth, standard solution) as electrolyte including open circuit potential (OCP) measurement, the electrochemical impedance spectroscopy (EIS) $(10 \mathrm{~Hz}-20 \mathrm{kHz})$ to obtain the setup resistance for $\mathrm{iR}$ compensation and the cyclic voltammogram (CV) recorded in the range of $(-0.5)-0 \mathrm{~V}$ at a scanning rate of $5 \mathrm{mV} / \mathrm{s}$. The detailed process of electrochemical measurements was performed as described in our previous study [32].

\section{Results and discussion}

\section{1 Characterization of single-source-precursors}

Taking the synthesis of PWA-3 as an example, the molecular structure of the sample prepared at room temperature for $24 \mathrm{~h}$ (PWA-3-RT) and $160{ }^{\circ} \mathrm{C}$ for $6 \mathrm{~h}$ (PWA-3-160) was investigated by FT-IR spectroscopy (Fig. 2). Besides, to trace the structural evolution during the preparation of single-source-precursor, the FT-IR spectra of starting materials including original AHPCS and DVB were also measured. The major 
(a)

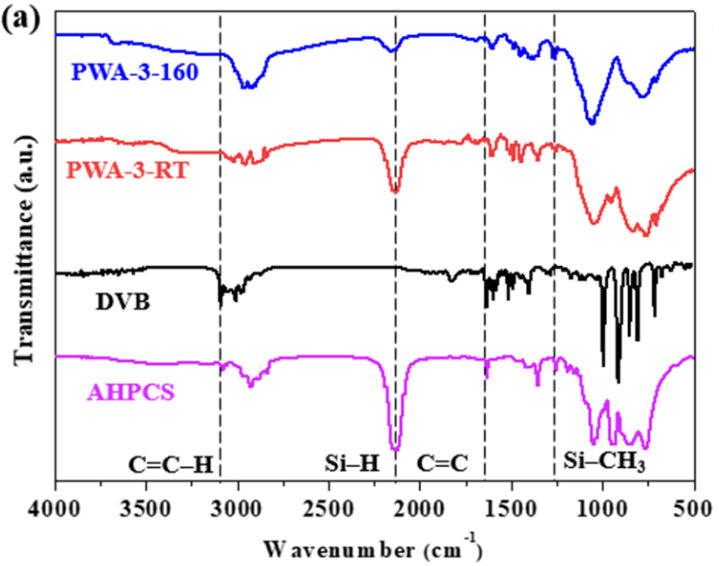

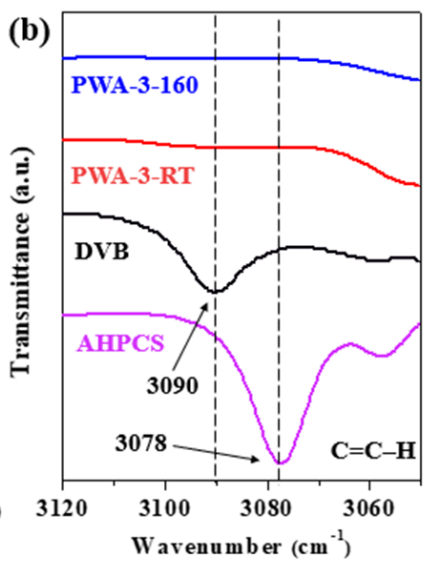

Fig. 2 FT-IR spectra of (a) AHPCS, DVB, PWA-3-RT, PWA-3-160 and (b) its region between 3050 and $3120 \mathrm{~cm}^{-1}$.

characteristic absorption peaks of AHPCS and DVB were explained in our previous study [35]. It is worth mentioning that compared with original AHPCS and DVB, the $\mathrm{C}-\mathrm{H}$ stretch of $-\mathrm{CH}=\mathrm{CH}_{2}$ at 3078 and 3090 $\mathrm{cm}^{-1}$ together with the $\mathrm{C}=\mathrm{C}$ stretch in $1630 \mathrm{~cm}^{-1}$ disappear in the sample PWA-3-RT. That means, even at the room temperature, the $\mathrm{C}=\mathrm{C}$ groups in $\mathrm{DVB}$ and in AHPCS can react with the $\mathrm{Si}-\mathrm{H}$ groups of AHPCS due to the hydrosilylation reaction, which generally occurs at $100-120{ }^{\circ} \mathrm{C}$ [2]. We assume that the introduction of $\mathrm{WCl}_{6}$, as the tungsten source, also played a catalytic role in the hydrosilylation reaction at the same time. According to our previous study [8], besides the hydrosilylation reaction, this system also can undergo dehydrochlorication reaction between $\mathrm{Si}-\mathrm{H}$ and $\mathrm{WCl}_{6}$ to consume $\mathrm{Si}-\mathrm{H}$ groups. As the temperature increases to $160{ }^{\circ} \mathrm{C}$, it can be observed that the absorption intensity of $\mathrm{Si}-\mathrm{H}$ in the PWA-3-160 further decreases. Since the characteristic absorption peaks of $\mathrm{C}=\mathrm{C}$ already disappear at the room temperature (PWA-3-RT), therefore, the weaker absorption intensity of $\mathrm{Si}-\mathrm{H}$ must be due to the dehydrochlorication reaction between $\mathrm{WCl}_{6}$ and remaining $\mathrm{Si}-\mathrm{H}$, based on the findings that the dehydrochlorication reaction can occur between metal chlorides and $\mathrm{Si}-\mathrm{H}$ groups $[8,9]$. The FT-IR results clearly demonstrate that the reaction between AHPCS and $\mathrm{WCl}_{6}$ results in the formation of the $\mathrm{W}$-containing single-source-precursor.

In summary, the reaction pathways during the synthesis of the single-source-precursor can be demonstrated in Fig. 3, including the hydrosilylation reaction between $\mathrm{C}=\mathrm{C}$ and $\mathrm{Si}-\mathrm{H}$ bonds as well as the dehydrochlorication reaction of $\mathrm{WCl}_{6}$ and $\mathrm{Si}-\mathrm{H}$ bonds.

\section{2 Composition and microstructure of ceramics}

Elemental analysis of the samples (PWA-2) annealed at $1300-1500{ }^{\circ} \mathrm{C}$ indicates that the ceramics originated from the addition of DVB as the carbon source have the higher carbon content (PWA-2-1300: $46.06 \mathrm{wt} \%$, PWA-2-1400: $44.59 \mathrm{wt} \%$, and PWA-2-1500: $46.23 \mathrm{wt} \%$ ) than that of pure $\mathrm{SiC}$ (around $20 \mathrm{wt} \%$ ) [16]. Additionally, compared with PWA-1 (PWA-1-1400: $40.96 \mathrm{wt} \%$ ), the higher ratio of DVB content can lead to the higher carbon content in the final ceramics prepared at the same temperature (PWA-2-1400: 44.59 $\mathrm{wt} \%)$. The phase compositions of the ceramics derived from W-containing precursors annealed at different temperatures were measured by XRD and the results are shown in Fig. 4. Figure 4(a) shows the phase evolution of the PWA-2 prepared at different annealing temperatures. The main peaks of W (JCPDS Card No. 04-0806), WC (JCPDS Card No. 51-0939), $\mathrm{W}_{2} \mathrm{C}$ (JCPDS Card No. 65-8766), and SiC (JCPDS Card No. 49-1428) are marked in the diagram. The ceramic obtained at $900{ }^{\circ} \mathrm{C}$ is amorphous. At $1100{ }^{\circ} \mathrm{C}$, the characteristic peaks of $\mathrm{W}$ appear. When the annealing temperature increases to $1200{ }^{\circ} \mathrm{C}$, the diffraction peak intensity of $\mathrm{W}$ increases significantly and the extremely weak WC crystallization diffraction peaks start to appear, indicating that the free carbon in the system reacted with $\mathrm{W}$ to form $\mathrm{WC}$ at this temperature. Then, the peaks belonging to $\mathrm{W}$ almost disappear when the temperature raises to $1300{ }^{\circ} \mathrm{C}$. Instead, the diffraction peaks of $\mathrm{WC}$ are stronger and a small amount of $\mathrm{W}_{2} \mathrm{C}$ crystallization diffraction peaks appear. In other words, at this temperature, the reduction 


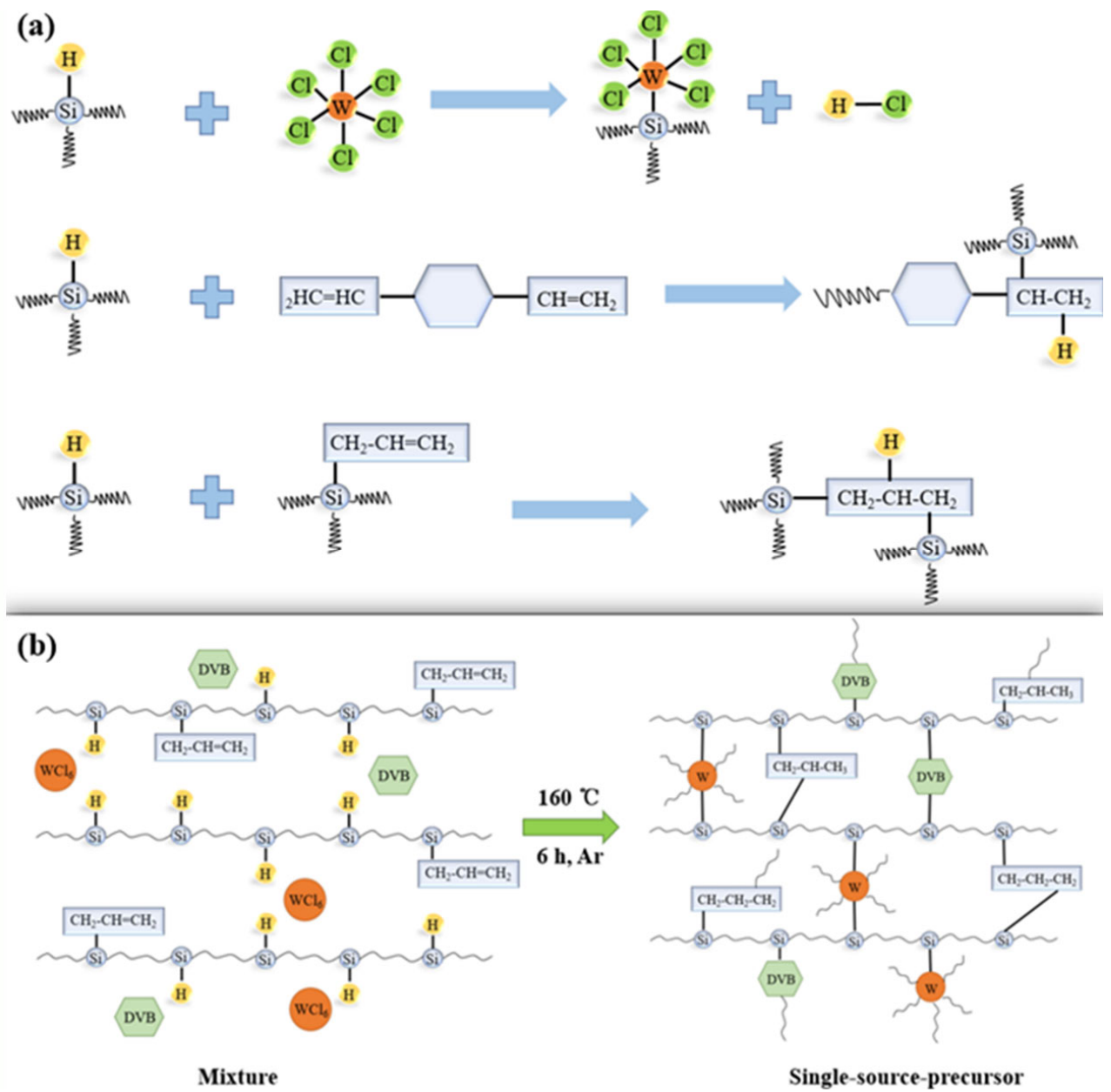

Fig. 3 (a) Idealized reaction path between the starting materials and (b) polymer chain morphologies of the single-source-precursor after crosslinking.

- $\mathrm{WC} \bullet \mathrm{W}_{2} \mathrm{C} \triangle \mathrm{SiC} \square \mathrm{W}$
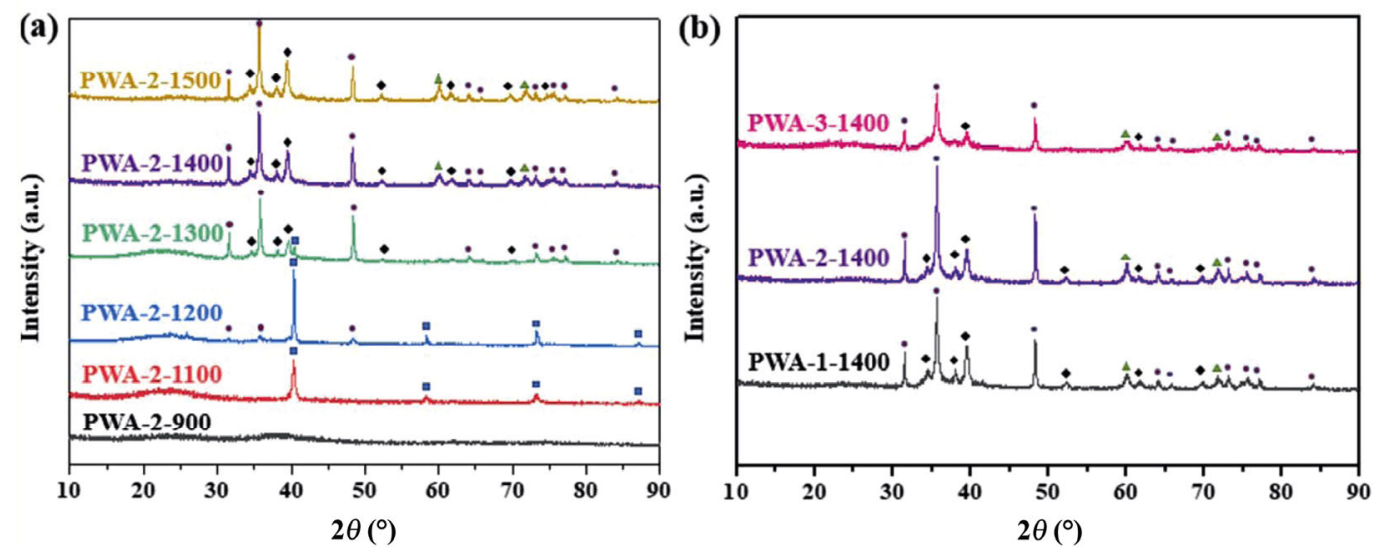

Fig. 4 XRD patterns of (a) PWA-2-derived ceramics annealed at different temperatures and (b) PWA-1, PWA-2, and PWA-3-derived ceramics annealed at $1400{ }^{\circ} \mathrm{C}$.

reaction between $\mathrm{W}$ and free carbon occurred to form $\mathrm{WC}$ and $\mathrm{W}_{2} \mathrm{C}$. At $1400{ }^{\circ} \mathrm{C}$, the diffraction peaks of $\mathrm{W}$ disappear completely, and the diffraction intensity of
$\mathrm{WC}$ and $\mathrm{W}_{2} \mathrm{C}$ tends to be stronger. Finally, when the temperature reached $1500{ }^{\circ} \mathrm{C}$, it can be seen that the crystallization peaks of WC decrease slightly, while 
that of $\mathrm{W}_{2} \mathrm{C}$ increase slightly. It is well known that, $\mathrm{W}_{2} \mathrm{C}$ has lower Gibbs free energy at the higher temperature, which means that $\mathrm{W}_{2} \mathrm{C}$ is more stable at the higher temperatures [38]. It is reasonable to assume that the following reaction may occur at $1500{ }^{\circ} \mathrm{C}$ $[33,39]$ :

$$
2 \mathrm{WC} \rightarrow \mathrm{W}_{2} \mathrm{C}+\mathrm{C}
$$

On the other hand, Fig. 4(b) shows the phase composition of samples prepared at $1400{ }^{\circ} \mathrm{C}$ with different DVB contents in the feed. With the increase of DVB content in the feed, we can clearly see that the diffraction peak intensity of $\mathrm{WC}$ is stronger, while that of $\mathrm{W}_{2} \mathrm{C}$ decreases slightly. The results suggest that the increase of carbon content in the system can strongly suppress the crystallization of $\mathrm{W}_{2} \mathrm{C}$ and promote the formation of near stoichiometric WC. The following reaction may occur when the carbon content of the system increases [40]:

$$
\mathrm{W}_{2} \mathrm{C}+\mathrm{C} \rightarrow 2 \mathrm{WC}
$$

With the increasing of DVB amount in the feed, the crystallinity of all phases decreases significantly, indicating that excessive DVB content would inhibit the crystallization of $\mathrm{WC}$ and $\mathrm{W}_{2} \mathrm{C}$. In summary, the phase conversion of $\mathrm{W}_{2} \mathrm{C}, \mathrm{WC}$, and $\mathrm{C}$ in the W-containing $\mathrm{SiC}$-based ceramics can be explained based on the following reversible reaction:

$$
\mathrm{W}_{2} \mathrm{C}+\mathrm{C} \rightleftharpoons 2 \mathrm{WC}
$$

An appropriate increase in carbon content will make the reaction move forward to form more WC crystals, while the higher reaction temperature will cause the reaction to move backward to form more $\mathrm{W}_{2} \mathrm{C}$.

Raman spectra were used to study the evolution of free carbon in the ceramic materials, and the results are shown in Fig. 5. The disorder-induced D-band at
$1350 \mathrm{~cm}^{-1}$ stands for the existence of disordered carbon, amorphous carbonaceous products or defects in graphite, while the graphite-like G-band at $1580 \mathrm{~cm}^{-1}$ is the result of in-plane bond stretching of ordering $\mathrm{sp}^{2}$ carbon [41]. Besides, the 2D- and G+D-bands at 2700 and $2920 \mathrm{~cm}^{-1}$ are due to the overtones or combination modes of the D- and G-bands [42,43]. Figure 5(a) illustrates the Raman spectra of the PWA-2 derived ceramics annealed at different temperatures (1300$\left.1500{ }^{\circ} \mathrm{C}\right)$. In the Raman spectra of sample PWA-2-1300, no signals for 2D $\left(2700 \mathrm{~cm}^{-1}\right)$ and $\mathrm{G}+\mathrm{D}\left(2920 \mathrm{~cm}^{-1}\right)$ bands can be detected, indicating that the segregated carbon in this sample is highly disordered at $1300{ }^{\circ} \mathrm{C}$. With the increase of temperature, the D- and G- bands reveal narrower line width, sharper peaks, and stronger intensities along with the gradually obvious $2 \mathrm{D}$ and $\mathrm{D}+\mathrm{G}$ bands. These phenomena indicate that the free carbon in the ceramics progressively transformed into more ordered graphite-like carbon. Moreover, graphitelike carbon is an important conductive phase in the ceramic materials, which is expected to improve the electrocatalytic activity of the electrocatalysts [35]. On the other hand, the Raman spectra of ceramics annealed at the same temperature $\left(1400{ }^{\circ} \mathrm{C}\right)$ are shown in Fig. 5(b). With increasing DVB content in the feed (PWA-1-1400 and PWA-2-1400), the D and G bands show smaller line width and the intensities of the $G$ and $2 \mathrm{D}\left(2700 \mathrm{~cm}^{-1}\right)$ bands grow gradually, indicating progressive structural ordering of the carbon. It is worth noting that the band intensity of the sample PWA-3-1400 is slightly reduced although more free carbon was introduced by the higher ratio of DVB content. This result means the higher free carbon content in the final ceramics cannot realize entire graphitization at this temperature.
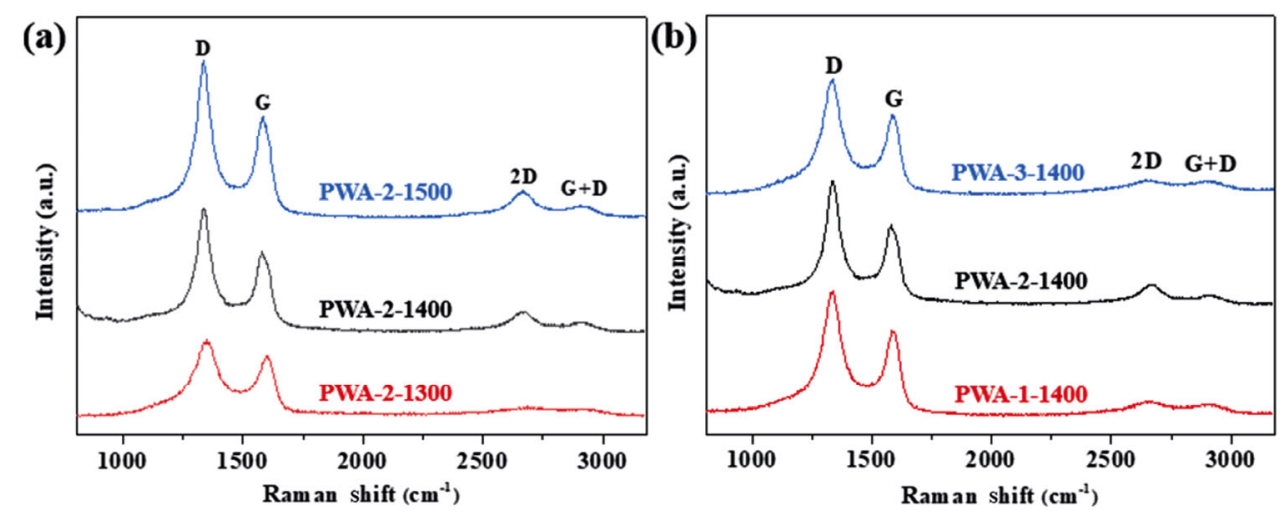

Fig. 5 Raman spectra of (a) PWA-2 derived ceramics annealed at different temperatures and (b) PWA-1, PWA-2, and PWA-3 derived ceramics annealed at $1400{ }^{\circ} \mathrm{C}$. 
The microstructures of ceramic samples PWA-2-1400, PWA-2-1500, and PWA-3-1400 were observed by SEM and TEM, shown in Fig. S1 in the Electronic Supplementary Material (ESM) and Fig. 6, respectively. The SEM images of samples (PWA-2-1400 and PWA-3-1400) presented in the ESM (Fig. S1) show the porous morphology of $\mathrm{W}$-containing SiC-based nanocomposites. The microstructures of sample PWA-2-1400 are shown in Figs. 6(a) and 6(b). We can observe that the W-containing particles are uniformly dispersed in the $\mathrm{SiC}$ ceramic matrix and the selected area electron diffraction (SAED) pattern shows clear Debye rings, which indicates the sample has an obvious crystalline feature. The high-resolution image (Fig. 6(b)) shows a WC crystallite (lattice spacing of ca. $0.19 \mathrm{~nm}$ ) with the size of $<100 \mathrm{~nm}$, which reflects the nanoscaled microstructure and fulfills the definition of nanocomposites. Besides, carbon and SiC (lattice spacing of ca. $0.25 \mathrm{~nm}$ ) can also be clearly detected. Figures 6(c) and 6(d) show the images of PWA-2 derived ceramic annealed at the higher temperature $\left(1500{ }^{\circ} \mathrm{C}\right)$. The SAED pattern also shows clear Debye rings, indicating a high crystallization. It is worth noting that, besides the WC crystallite, $\mathrm{W}_{2} \mathrm{C}$ nanoparticles (lattice spacing of ca.

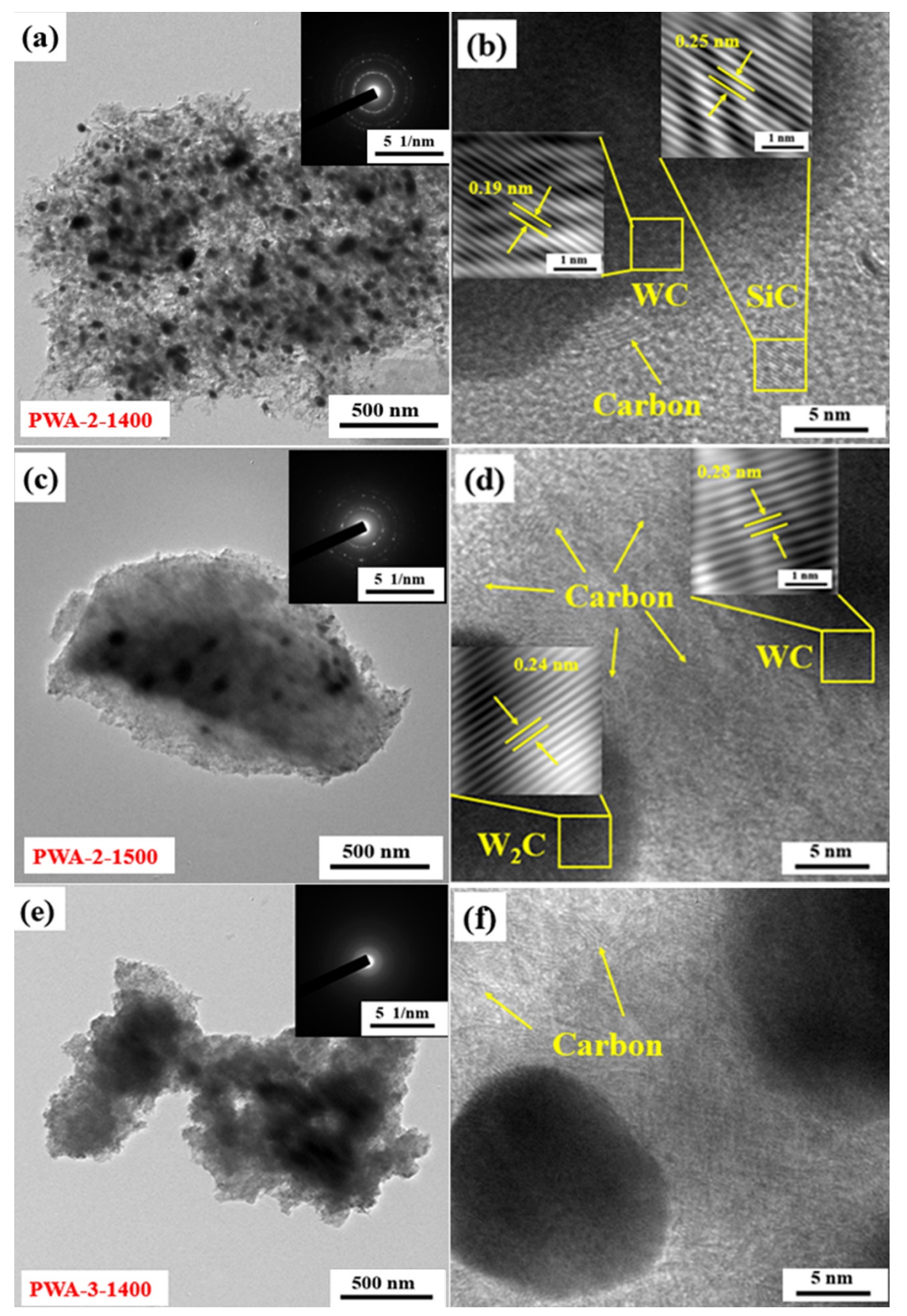

Fig. 6 TEM and HRTEM images of (a, b) PWA-2-1400, (c, d) PWA-2-1500, and (e, f) PWA-3-1400. 
$0.24 \mathrm{~nm}$ ) can be detected, which confirms that the WC phase is partially transformed into $\mathrm{W}_{2} \mathrm{C}$, after annealing at $1500{ }^{\circ} \mathrm{C}$ (Fig. 6(d)). The TEM results agree well with the XRD patterns shown in Fig. 4. In comparison, in the TEM images of the sample PWA-3-1400 (Figs. 6(e) and 6(f)), it is difficult to identify the crystalline phases (W-containing particles or $\mathrm{SiC}$ ) by SAED. In addition, besides some carbon, $\mathrm{WC}, \mathrm{SiC}$, and $\mathrm{W}_{2} \mathrm{C}$ crystalline nanoparticles cannot be clearly observed in the HRTEM image (Fig. 6(f)). Those results confirm that the crystal growth of the $\mathrm{W}$-containing particles and $\mathrm{SiC}$ is strongly retarded, which is consistent with the XRD results.

\section{3 Porosity characteristics}

The $\mathrm{N}_{2}$ adsorption-desorption curves are shown in Figs. 7(a) and 7(c). Except for the sample PWA-2-1300, other samples reveal typical characteristic type-IV isotherms, indicating that the obtained materials have mesoporous properties. The BET specific surface area (SSA) of the PWA-2-1300 is only $67.2 \mathrm{~m}^{2} / \mathrm{g}$, which is mainly due to the decomposition of uncrosslinked linear PS during pyrolysis. However, compared with our previous study [34], the ability of the pore former (PS) for increasing SSA in this system is limited. We assume that this result is because the limited dispersibility of PS in the W-containing single-sourceprecursor, which can only produce macropores in the composites and decrease the SSA. This assumption can be proven by the pore size distribution shown in Fig. 7(b). Then, after heating up to $1400{ }^{\circ} \mathrm{C}$, the SSA of PWA-2-1400 increases to $209.6 \mathrm{~m}^{2} / \mathrm{g}$, more than three times of the PWA-2-1300, which is due to the overflow of small molecule gas produced by carbothermal reaction at this temperature range. The viscous flow of ceramic materials at higher temperature will make the ceramic gradually densified, coupled with the completion of carbothermal reaction. As a result, when the temperature rises to $1500{ }^{\circ} \mathrm{C}$, the SSA of the PWA-2-1500 decreases to $169.4 \mathrm{~m}^{2} / \mathrm{g}$. Figure 7(b) reveals the pore size distribution of every sample shown in Fig. 7(a). As mentioned before, it can be seen

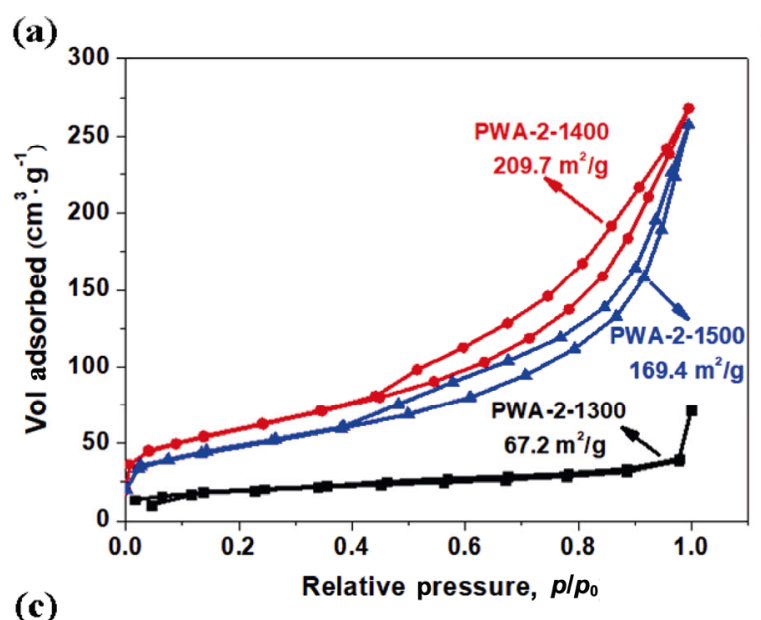

(b)
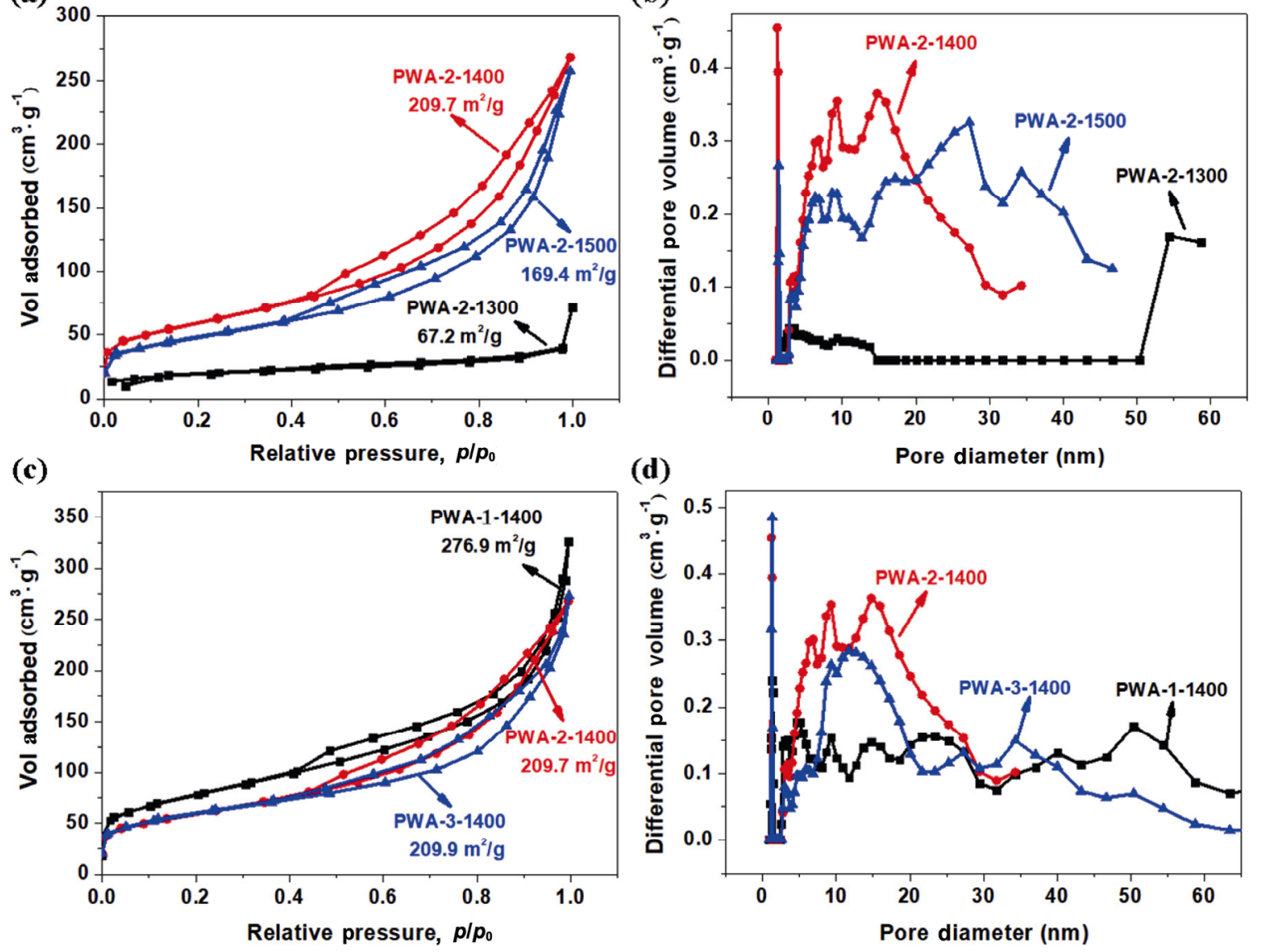

(d)

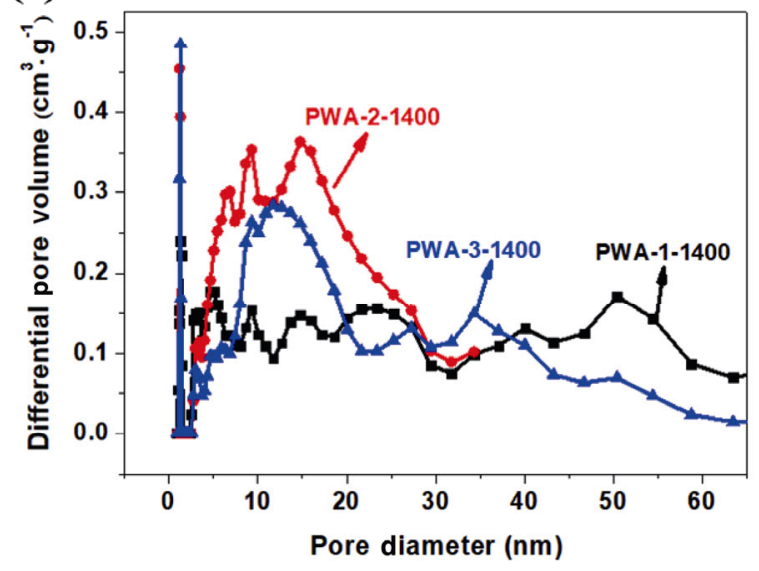

Fig. $7 \mathrm{~N}_{2}$ adsorption-desorption isotherms ( $\mathrm{a}, \mathrm{c}$ ), pore size distribution (b, d) of PWA-2 derived ceramics annealed at different temperatures and PWA-1, PWA-2, and PWA-3-derived ceramics annealed at $1400{ }^{\circ} \mathrm{C}$. 
that the pore size of the sample (PWA-2-1300) is mainly above $50 \mathrm{~nm}$ at $1300{ }^{\circ} \mathrm{C}$. With the temperature increasing to $1400{ }^{\circ} \mathrm{C}$, a large number of mesopores (with the pore diameter in the range of 2-50 nm) and micropores (with the pore diameter $<2 \mathrm{~nm}$ ) appear in the material due to the carbothermal reaction. Finally, for the sample PWA-2-1500, the higher annealing temperature at $1500{ }^{\circ} \mathrm{C}$ can lead to a partial collapse of pores and the increase of pore size. On the other hand, the $\mathrm{N}_{2}$ adsorption-desorption curves of the synthesized ceramics prepared at $1400{ }^{\circ} \mathrm{C}$ with different DVB contents in the feed are shown in Fig. 7(c). It is worth noting that the SSA of PWA-1-1400 with low carbon content is $276.9 \mathrm{~m}^{2} / \mathrm{g}$, which is higher than that of
PWA-2-1400 (209.7 $\left.\mathrm{m}^{2} / \mathrm{g}\right)$ and PWA-3-1400 (209.9 $\mathrm{m}^{2} / \mathrm{g}$ ). Figure $7(\mathrm{~d})$ shows the pore size distribution of every ceramic sample shown in Fig. 7(c), which again confirms the mesoporous feature. The specific surface area and average pore diameter of all samples are listed in Table $\mathrm{S} 1$ in the ESM. In conclusion, the decomposition of PS and the carbothermal reaction during high temperature annealing play the crucial role to influence specific surface area and pore size distribution of the porous W-containing SiC-based nanocomposites. And based on the above data analysis (FT-IR spectra, XRD, TEM, and BET method), the evolution process of materials from precursor to ceramic material is shown in Fig. 8.

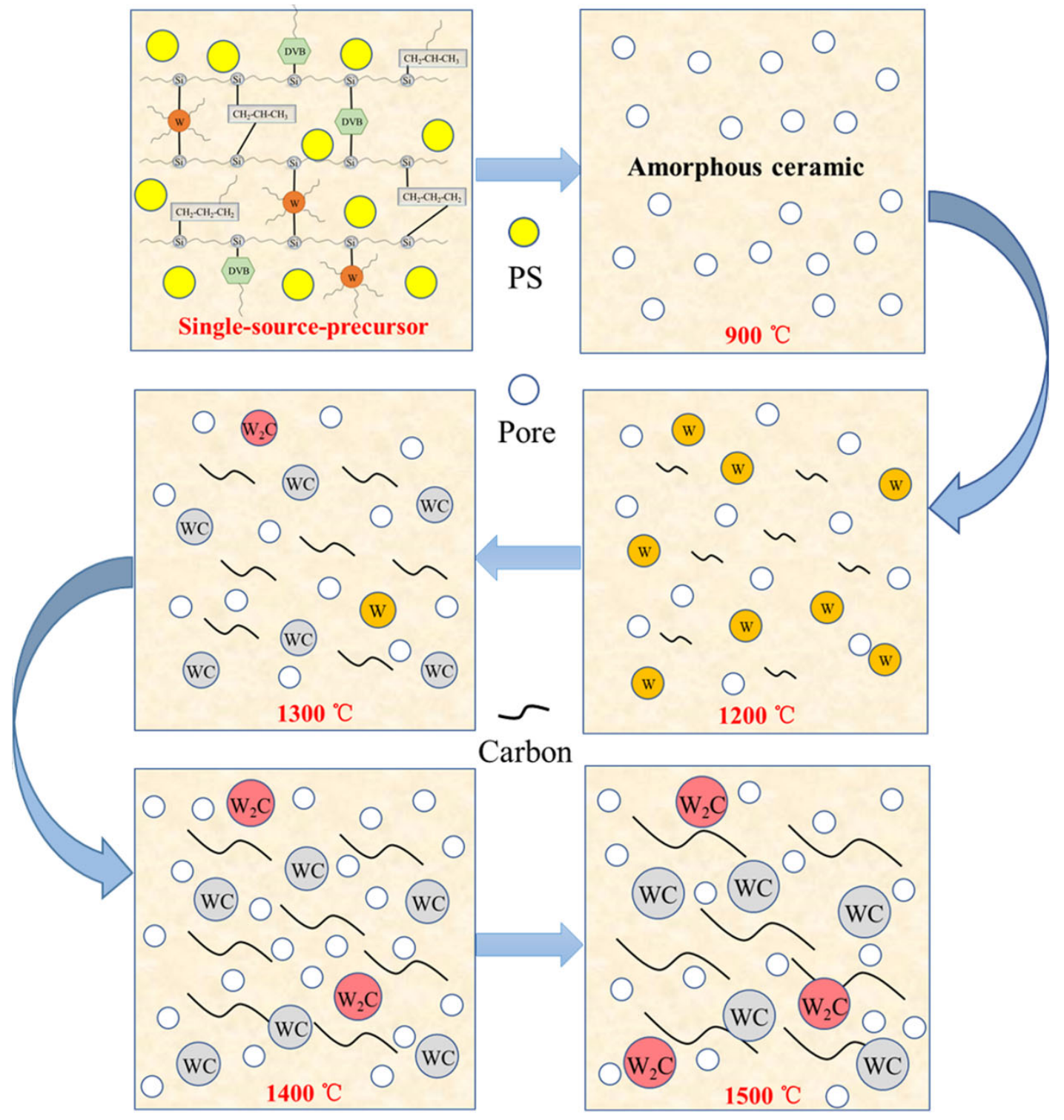

Fig. 8 Evolution mechanism diagram of the W-containing SiC-based nanocomposites. 


\section{4 Electrocatalytic performance}

The HER performance of the obtained ceramics was evaluated under acidic conditions $\left(0.5 \mathrm{~mol} / \mathrm{L} \mathrm{H}_{2} \mathrm{SO}_{4}\right)$. The ceramic powders were deposited on the glassy carbon electrode with the optimized mass loading of $0.95-1.00 \mathrm{mg} / \mathrm{cm}^{2}$. As shown in Fig. 9, all samples reveal electrocatalytic activity. In these ceramic materials, $\mathrm{SiC}$ is only used as a porous carrier for active particles, and its electrocatalytic performance for HER is poor [34]. Thus, the catalytic activity is mainly due to the existence of $\mathrm{WC}$ and $\mathrm{W}_{2} \mathrm{C}$ nanoparticles. Generally speaking, the smaller the overpotential is, the better the electrocatalytic performance is (under the same current density). The $\eta_{10}$ (the overpotential at the current density of $10 \mathrm{~mA} \cdot \mathrm{cm}^{-2}$ ) is often used to evaluate the performance of catalytic materials [23]. Figure 9(a) shows the polarization curves of the PWA-2 derived ceramics annealed at different temperatures, and the electrocatalytic performance of the samples annealed at $1300{ }^{\circ} \mathrm{C}$ (PWA-2-1300, $\eta_{10}=286 \mathrm{mV}$ ) and $1400{ }^{\circ} \mathrm{C}$ (PWA- 2-1400, $\eta_{10}=289 \mathrm{mV}$ ) is better than that of the sample prepared at $1500{ }^{\circ} \mathrm{C}$ (PWA-2-1500, $\eta_{10}=310 \mathrm{mV}$ ). During the increase of annealing temperatures, there are so many factors in this system (such as phase compositions, degree of crystallization of W-containing phase, ordering of the carbon, and SSA), which can influence the electrocatalytic performance of W-containing SiC-based nanocomposites. Besides, there is still a dispute about which of $\mathrm{WC}$ and $\mathrm{W}_{2} \mathrm{C}$ has better catalytic performance for HER [33]. Thus, the specific influencing factor of electrocatalytic performance of the samples annealed at different temperatures will not be discussed in this work in detail. On the other hand, at the same annealing temperature (Fig. 9(b)), with the increase of DVB content from 2 to $3 \mathrm{~g}$ in the feed, the $\eta_{10}$ of the ceramics decreases from $378 \mathrm{mV}$ (PWA1-1400) to $289 \mathrm{mV}$ (PWA-2-1400). The enhanced electrocatalytic performance is due to the fact that the addition of DVB in the preceramic polymer can enhance the carbon content in the resultant ceramics and improve the electrical conductivity of the $\mathrm{W}$-containing nanocomposites, which is consistent with our previous work related to the $\mathrm{Mo}_{4.8} \mathrm{Si}_{3} \mathrm{C}_{0.6} /$ $\mathrm{C} / \mathrm{SiC}$ ceramic nanocomposites [35]. Then, with the further increasing of DVB content in the feed, the $\eta_{10}$ significantly increases to $345 \mathrm{mV}$ (PWA-3-1400) instead. This behavior could be explained by the inhibited crystallization of catalytic particles (WC, $\mathrm{W}_{2} \mathrm{C}$ ) and the less ordered free carbon (conductive phase), as proved by the XRD (Fig. 4) and Raman (Fig. 5) results, resulting in a decrease in the number of active catalytic sites and conductivity. In summary, although the obtained W-containing SiC-based nanocomposites exhibit HER activity, the minimum overpotential in this system is not outstanding compared with other reported W-based compounds with conductive supports (Table S2 in the ESM). Therefore, how to improve the conductivity of the material, maintain high specific surface area and enhance the crystallinity of $\mathrm{WC} / \mathrm{W}_{2} \mathrm{C}$ nanoparticles will become the focus of the future work.
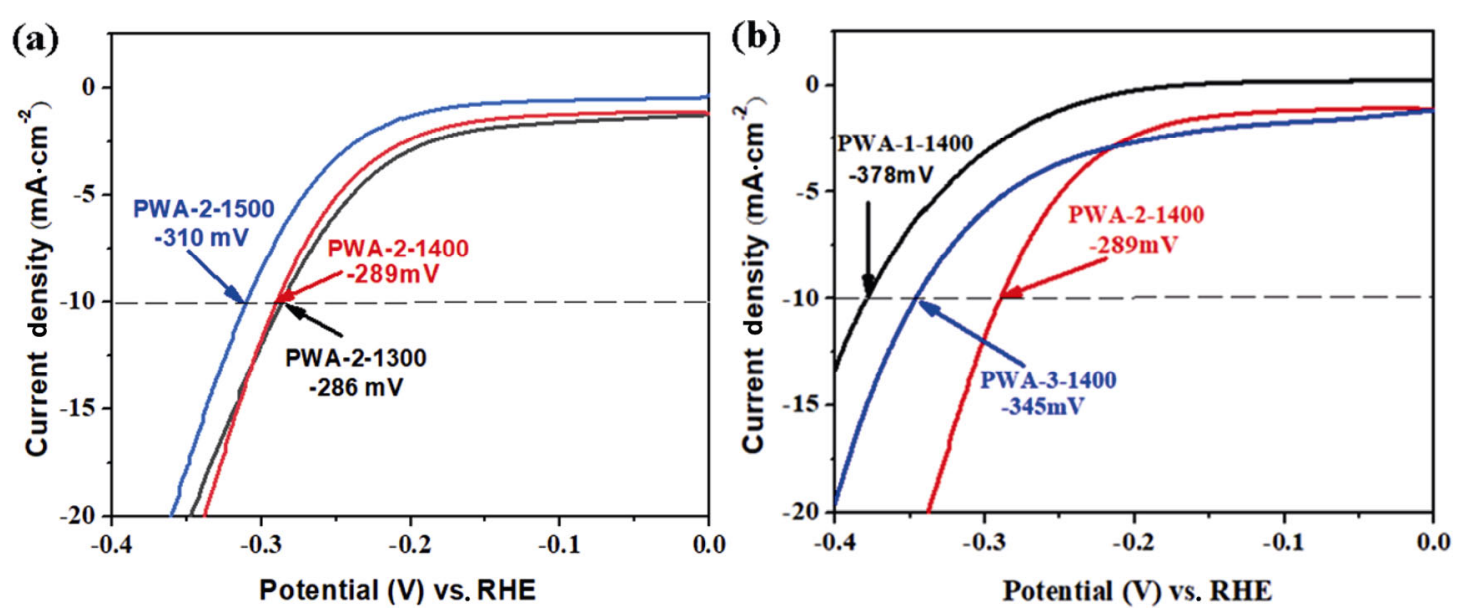

Fig. 9 Polarization curves (iR corrected) of (a) PWA-2 derived ceramics annealed at different temperatures and (b) PWA-1, PWA-2, and PWA-3-derived ceramics annealed at $1400{ }^{\circ} \mathrm{C}$. 


\section{Conclusions}

In this study, porous $\mathrm{W}$-containing SiC-based ceramic nanocomposites with high total carbon content (above $40 \mathrm{wt} \%$ ) has been synthesized by a PDC route starting from a novel W-containing single-source-precursor obtained by modifying the AHPCS with the $\mathrm{WCl}_{6}$ as a tungsten source and the addition of DVB as an additional carbon source. It was proven by FTIR that the formation of single-source-precursor was realized through hydrosilylation and dehydrochlorination reactions. The phase composition analysis of final ceramics by XRD reveals that an appropriate increase of DVB content in the feed is helpful to form near stoichiometric WC, but excessive addition will inhibit the crystallization of the material. The BET results show that high specific surface area $\left(169.4-276.9 \mathrm{~m}^{2} / \mathrm{g}\right.$ ) of the samples can be maintained at the high annealing temperature $\left(1400-1500{ }^{\circ} \mathrm{C}\right)$ due to the carbothermal reduction reaction. Finally, the obtained W-containing SiC-based ceramic nanocomposites exhibit good electrocatalytic properties $\left(\eta_{10}=286 \mathrm{mV}\right)$ suitable for the electrochemical hydrogen evolution. This work further extends the application of PDCs in the field of HER for electrochemical water splitting.

\section{Acknowledgements}

Zhaoju $\mathrm{Yu}$ thanks the National Natural Science Foundation of China (Nos. 51872246 and 52061135102 ) for financial support.

\section{Electronic Supplementary Material}

Supplementary material is available in the online version of this article at https://doi.org/10.1007/s40145-021-0508-8.

\section{References}

[1] Colombo P, Mera G, Riedel R, et al. Polymer-derived ceramics: 40 years of research and innovation in advanced ceramics. J Am Ceram Soc 2010, 93: 1805-1837.

[2] Ionescu E, Kleebe HJ, Riedel R. Silicon-containing polymer-derived ceramic nanocomposites (PDC-NCs): Preparative approaches and properties. Chem Soc Rev 2012, 41: 5032-5052.

[3] Modena S, Sorarù GD, Blum Y, et al. Passive oxidation of an effluent system: The case of polymer-derived SiCO. $J$ Am Ceram Soc 2005, 88: 339-345.
[4] Wang YG, Fei WF, An LN. Oxidation/corrosion of polymer-derived SiAlCN ceramics in water vapor. $J \mathrm{Am}$ Ceram Soc 2006, 89: 1079-1082.

[5] Rouxel T, Soraru GD, Vicens J. Creep viscosity and stress relaxation of gel-derived silicon oxycarbide glasses. $\mathrm{J} \mathrm{Am}$ Ceram Soc 2001, 84: 1052-1058.

[6] Bernard S, Weinmann M, Cornu D, et al. Preparation of high-temperature stable $\mathrm{SiBCN}$ fibers from tailored single source polyborosilazanes. J Eur Ceram Soc 2005, 25: 251-256.

[7] Cornu D, Bernard S, Duperrier S, et al. Alkylaminoborazine-based precursors for the preparation of boron nitride fibers by the polymer-derived ceramics (PDCs) route. J Eur Ceram Soc 2005, 25: 111-121.

[8] Yu ZJ, Yang YJ, Mao KW, et al. Single-source-precursor synthesis and phase evolution of SiC-TaC-C ceramic nanocomposites containing core-shell structured TaC@C nanoparticles. $J$ Adv Ceram 2020, 9: 320-328.

[9] Yu ZJ, Lv X, Lai SY, et al. ZrC-ZrB $\mathrm{Zr}_{2}-\mathrm{SiC}$ ceramic nanocomposites derived from a novel single-source precursor with high ceramic yield. J Adv Ceram 2019, 8: 112-120.

[10] Sun J, Wen QB, Li T, et al. Phase evolution of SiOC-based ceramic nanocomposites derived from a polymethylsiloxane modified by Hf- and Ti-alkoxides. $J$ Am Ceram Soc 2020, 103: 1436-1445.

[11] Sun J, Li T, Reitz A, et al. High-temperature stability and oxidation behavior of $\mathrm{SiOC} / \mathrm{HfO}_{2}$ ceramic nanocomposite in air. Corros Sci 2020, 175: 108866.

[12] Nishimura T, Haug R, Bill J, et al. Mechanical and thermal properties of Si-C-N material from polyvinylsilazane. $J$ Mater Sci 1998, 33: 5237-5241.

[13] Wilson AM, Zank G, Eguchi K, et al. Pore creation in silicon oxycarbides by rinsing in dilute hydrofluoric acid. Chem Mater 1997, 9: 2139-2144.

[14] Yu ZJ, Zhang P, Feng Y, et al. Template-free synthesis of porous $\mathrm{Fe}_{3} \mathrm{O}_{4} / \mathrm{SiOC}(\mathrm{H})$ nanocomposites with enhanced catalytic activity. J Am Ceram Soc 2016, 99: 2615-2624.

[15] Yu ZJ, Lv X, Mao KW, et al. Role of in situ formed free carbon on electromagnetic absorption properties of polymer-derived SiC ceramics. J Adv Ceram 2020, 9: 617-628.

[16] Feng Y, Yang YJ, Wen QB, et al. Dielectric properties and electromagnetic wave absorbing performance of single-source-precursor synthesized $\mathrm{Mo}_{4.8} \mathrm{Si}_{3} \mathrm{C}_{0.6} / \mathrm{SiC} / \mathrm{C}$ free nanocomposites with an in situ formed nowotny phase. ACS Appl Mater Interfaces 2020, 12: 16912-16921.

[17] Liew LA, Liu YP, Luo RL, et al. Fabrication of SiCN MEMS by photopolymerization of pre-ceramic polymer. Sensor Actuat A: Phys 2002, 95: 120-134.

[18] Liew L, Zhang W, An L, et al. Ceramic MEMS. Am Ceram Soc Bull 2000, 80: 25.

[19] Meng LL, Zhang XF, Tang YS, et al. Hierarchically porous silicon-carbon-nitrogen hybrid materials towards highly efficient and selective adsorption of organic dyes. Sci Rep 
2015, 5: 7910.

[20] Feng Y, Lai SY, Yang L, et al. Polymer-derived porous $\mathrm{Bi}_{2} \mathrm{WO}_{6} / \mathrm{SiC}(\mathrm{O})$ ceramic nanocomposites with high photodegradation efficiency towards Rhodamine B. Ceram Int 2018, 44: 8562-8569.

[21] Hojamberdiev M, Prasad RM, Morita K, et al. Templatefree synthesis of polymer-derived mesoporous $\mathrm{SiOC} / \mathrm{TiO}_{2}$ and $\mathrm{SiOC} / \mathrm{N}$-doped $\mathrm{TiO}_{2}$ ceramic composites for application in the removal of organic dyes from contaminated water. Appl Catal B: Environ 2012, 115-116: 303-313.

[22] Hojamberdiev M, Prasad RM, Morita K, et al. Polymerderived mesoporous $\mathrm{SiOC} / \mathrm{ZnO}$ nanocomposite for the purification of water contaminated with organic dyes. Microporous Mesoporous Mater 2012, 151: 330-338.

[23] Li XM, Hao XG, Abudula A, et al. Nanostructured catalysts for electrochemical water splitting: Current state and prospects. J Mater Chem A 2016, 4: 11973-12000.

[24] Zou XX, Zhang Y. Noble metal-free hydrogen evolution catalysts for water splitting. Chem Soc Rev 2015, 44: $5148-5180$.

[25] Zhang LL, Xiao J, Wang HY, et al. Carbon-based electrocatalysts for hydrogen and oxygen evolution reactions. ACS Catal 2017, 7: 7855-7865.

[26] Nørskov JK, Bligaard T, Logadottir A, et al., Trends in the exchange current for hydrogen evolution. $J$ Electrochem Soc 2005, 152: J23.

[27] Chen WF, Muckerman JT, Fujita E. Recent developments in transition metal carbides and nitrides as hydrogen evolution electrocatalysts. Chem Commun 2013, 49: 8896-8909.

[28] Wang FM, Shifa TA, Zhan XY, et al. Recent advances in transition-metal dichalcogenide based nanomaterials for water splitting. Nanoscale 2015, 7: 19764-19788.

[29] Zeng M, Li YG. Recent advances in heterogeneous electrocatalysts for the hydrogen evolution reaction. $J$ Mater Chem A 2015, 3: 14942-14962.

[30] Wirth S, Harnisch F, Weinmann M, et al. Comparative study of IVB-VIB transition metal compound electrocatalysts for the hydrogen evolution reaction. Appl Catal B: Environ 2012, 126: 225-230.

[31] Regmi YN, Waetzig GR, Duffee KD, et al. Carbides of group IVA, VA and VIA transition metals as alternative HER and ORR catalysts and support materials. $J$ Mater Chem A 2015, 3: 10085-10091.

[32] Murthy AP, Madhavan J, Murugan K. Recent advances in hydrogen evolution reaction catalysts on carbon/carbonbased supports in acid media. J Power Sources 2018, 398: 9-26.

[33] Fan XJ, Zhou HQ, Guo X. WC nanocrystals grown on vertically aligned carbon nanotubes: An efficient and stable electrocatalyst for hydrogen evolution reaction. ACS Nano 2015, 9: 5125-5134.
[34] Feng Y, Yu ZJ, Schuch J, et al. Nowotny phase $\mathrm{Mo}_{3+2 x} \mathrm{Si}_{3} \mathrm{C}_{0.6}$ dispersed in a porous $\mathrm{SiC} / \mathrm{C}$ matrix: A novel catalyst for hydrogen evolution reaction. $J$ Am Ceram Soc 2020, 103: 508-519.

[35] Feng Y, Yu ZJ, Riedel R. Enhanced hydrogen evolution reaction catalyzed by carbon-rich $\mathrm{Mo}_{4.8} \mathrm{Si}_{3} \mathrm{C}_{0.6} / \mathrm{C} / \mathrm{SiC}$ nanocomposites via a PDC approach. J Am Ceram Soc 2020, 103: 1385-1395.

[36] Bazarjani MS, Müller MM, Kleebe HJ, et al. In situ formation of tungsten oxycarbide, tungsten carbide and tungsten nitride nanoparticles in micro-and mesoporous polymer-derived ceramics. J Mater Chem A 2014, 2: 10454-10464.

[37] Huang TH, Yu ZJ, He XM, et al. One-pot synthesis and characterization of a new, branched polycarbosilane bearing allyl groups. Chin Chem Lett 2007, 18: 754-757.

[38] Li JN, Li HQ, Wang M, et al. Applications of WC-based composites rapid synthesized by consumable electrode in situ metallurgy to cutting pick. Int $J$ Refract Met Hard Mater 2012, 35: 132-137.

[39] Erfanmanesh M, Abdollah-Pour H, MohammadianSemnani $\mathrm{H}$, et al. Kinetics and oxidation behavior of laser clad WC-Co and Ni/WC-Co coatings. Ceram Int 2018, 44: 12805-12814.

[40] Wang Q, Cao FY, Chen QW. Synthesis of hexagonal tungsten carbide in tungsten-sodium and supercritical carbon dioxide system. Mater Chem Phys 2006, 95: 113-116.

[41] Mera G, Navrotsky A, Sen S, et al. Polymer-derived SiCN and SiOC ceramics - structure and energetics at the nanoscale. J Mater Chem A 2013, 1: 3826-3836.

[42] Wen QB, Feng Y, Yu ZJ, et al. Microwave absorption of $\mathrm{SiC} / \mathrm{HfC}_{x} \mathrm{~N}_{1-x} / \mathrm{C}$ ceramic nanocomposites with $\mathrm{HfC}_{x} \mathrm{~N}_{1-x^{-}}$ carbon core-shell particles. J Am Ceram Soc 2016, 99: 2655-2663.

[43] Wen QB, Yu ZJ, Riedel R. The fate and role of in situ formed carbon in polymer-derived ceramics. Prog Mater Sci 2020, 109: 100623.

Open Access This article is licensed under a Creative Commons Attribution 4.0 International License, which permits use, sharing, adaptation, distribution and reproduction in any medium or format, as long as you give appropriate credit to the original author(s) and the source, provide a link to the Creative Commons licence, and indicate if changes were made.

The images or other third party material in this article are included in the article's Creative Commons licence, unless indicated otherwise in a credit line to the material. If material is not included in the article's Creative Commons licence and your intended use is not permitted by statutory regulation or exceeds the permitted use, you will need to obtain permission directly from the copyright holder.

To view a copy of this licence, visit http://creativecommons.org/licenses/by/4.0/. 